\title{
İğde Çekirdeğinden Elde Edilen Aktif Karbon Kullanılarak Sulu Çözeltilerden Pb(II) Adsorpsiyonun İncelenmesi: İzoterm ve Kinetik
}

\author{
Orhan BAYTAR ${ }^{*}$, Ayhan Abdullah CEYHAN ${ }^{2}$, Ömer ŞAHIN ${ }^{1}$ \\ ${ }^{1}$ Siirt Üniversitesi, Kimya Mühendisliği, Bölümü, Sïrt \\ ${ }^{2}$ Selçuk Üniversitesi, Kimya Mühendisliği, Bölümü, Siirt
}

\begin{abstract}
$\ddot{O} z$
$\mathrm{Bu}$ çalışmada, önceki çalışmamızda $\mathrm{ZnCI}_{2}$ aktifleştiricisi kullanılarak kimyasal aktivasyon yöntemi ile iğde çekirdeğinden elde edilen $1836 \mathrm{~m}^{2} / \mathrm{g}$ BET yüzey alanına sahip aktif karbon kullanılarak sulu çözeltilerden $\mathrm{Pb}(\mathrm{II})$ adsorpsiyonu incelenmiştir. Bu amaçla, çözelti pH'ı, aktif karbon miktarı, çözelti başlangıç derişimi ve işlem sıcaklığı parametrelerinin $\mathrm{Pb}(\mathrm{II})$ adsorpsiyonuna etkileri ayrı ayrı incelenmiştir. Artan sıcaklık ve aktif karbon miktarı ile $\mathrm{Pb}(\mathrm{II})$ giderim yüzdesinin arttı̆̆ belirlenmiş̧tir. Adsorpsiyon denge verilerinin Langmuir izotermine uyduğu tespit edilmiş olup, maksimum adsorpsiyon kapasitesi (qmaks) çözelti başlangıç $\mathrm{pH}$ değeri pH=4'de 86,207 mg.g ${ }^{-1}$ olarak bulunmuştur. Sulu çözeltiden $\mathrm{Pb}(\mathrm{II})$ adsorpsiyon kinetiğinin Elovich kinetik model ile uyumlu olduğu tespit edilmiştir. Partikül içi difüzyon modeli sonuçlarına göre adsorpsiyon işleminin birden fazla basamakta gerçekleştiği ve difüzyonu kontrol eden basamağın en küçük difüzyon katsayısına $(1,455)$ sahip olan 3. basamak olduğu belirlenmiştir.
\end{abstract}

Anahtar kelimeler: $\mathrm{Pb}(\mathrm{II})$, adsorpsiyon, izoterm, kimyasal aktivasyon, $\mathrm{ZnCl}_{2}$.

\section{Investigation of $\mathrm{Pb}$ (II) Adsorption From Aqueous Solutions Using Activated Carbon Obtained From Elaeagnus Seed: Isotherm and Kinetic}

\begin{abstract}
In our previous study, activated carbon with a BET surface area of $1836 \mathrm{~m} 2 / \mathrm{g}$ was obtained by the chemical activation method from elaeagnus seed. $\mathrm{ZnCl}_{2}$ was used as a activator in the synthesis of actived carbon. In this study, $\mathrm{Pb}$ (II) adsorption from aqueous solutions was investigated using this activated carbon. For this purpose, the effects of some parameters such as solution $\mathrm{pH}$, amount of activated carbon, solution initial concentration and treatment temperature $\mathrm{Pb}$ (II) adsorption were separately investigated. It was determined that the percentage of $\mathrm{Pb}$ (II) removal increases with increasing temperature and amount of activated carbon. It was found that adsorption equilibrium data are consistent with Langmuir isotherm. Thus, the maximum adsorption capacity $\left(\mathrm{q}_{\max }\right)$ was found as $86.207 \mathrm{mg} \cdot \mathrm{g}^{-1}$ at $\mathrm{pH}=4$. The adsorption kinetics of the aqueous solution $\mathrm{Pb}$ (II) were found to be consistent with the Elovich kinetic model. According to the results of the particle diffusion model, it was determined that the adsorption process is performed in more than one step and the third step has the smallest diffusion coefficient $(1,455)$ of the diffusion controlling step.
\end{abstract}

Keywords: $\mathrm{Pb}(\mathrm{II})$, adsorption, isotherm, chemical activation, $\mathrm{ZnCl}_{2}$

\section{Giriş}

Dünyanın kabuğunu oluşturan ağır metaller(kurşun, kadmiyum, krom vb.) genel itibariyle zehirlidirler. Eser miktarda da olsa ağır metallere maruz kalınmasının canlı sağlı̆̆ını etkileyeceği bilinmekle birlikte, yüksek derişimlerde çinko, kadmiyum, nikel, kurşun ve diğer ağır metaller başta insan fizyolojisi ve diğer biyolojik sistemler üzerinde ciddi riskler taşımaktadır [1]. Ağır metaller bulundukları ortamda kendi kendine bozulmaz veya yok olmazlar. Bu sebeple, içme sularının kirlenmesi, havanın kirlenmesi ve gıda zinciri yoluyla zehirlenmelere sebep olabilmektedirler [2]. Endüstride ağır metal kullanımının

*Sorumlu yazar: orhanbaytar@siirt.edu.tr

Geliş Tarihi: 09.05.2018, Kabul Tarihi: 06.09.2018 
artması sonucu doğal sulardaki metalik maddelerin sebep olduğu kirlilik artmaktadır [3]. Ağır metallerin sulardan giderilmesi için adsorpsiyon, çöktürme, membran filtrasyonu ve iyon değişimi gibi teknolojiler kullanılmaktadır [4]. Atık sulardan ağır metallerin, organik kirleticilerin ve boyarmaddelerin giderilmesinde hem ekonomik olması hem de etkin giderim sağlaması açısından adsorpsiyon işlemi önemli bir alternatiftir [5]. Suların temizlenmesi işleminde, aktif karbon, silika ve grafen gibi farklı adsorbentler yaygın biçimde kullanılmaktadır [6].

Elaeagnus angustifolia L. bitkisi, halk arasında iğde olarak bilinen Elaeagnaceae familyasına ait bir bitki türüdür. Genellikle çalı yapılı olup kışın yapraklarını döker. İğde bitkisi ağaçlarının boyu 7 m'ye kadar uzayabilmektedir. Daha çok Asya Kıtasının orta ve batısında, Gobi çölünde, Alplerde, Akdeniz bölgesinde bulunmaktadır. Türkiye'de ise tüm Karadeniz, Marmara, Güney Anadolu ve Güney Doğu Anadolu olmak üzere yaygın bir şekilde bulunmaktadır. Davis'e göre iğde bitkisinin sadece bir türü Türkiye'de bulunmaktadır. İğde bitkisi genellikle doğal olarak bulunduğu gibi kültür yetiştiriciliği de yapılmaktadır. Hızlı şekilde büyüyebilen bir ağaç türü olan iğde ağacının meyveleri (iğde çekirdeği) karbonhidratlar, protein, organik maddeler, amino asitler ve vitaminler bakımından oldukça zengindir. Meyvelerinin şekilleri eliptik olup, kırmızımsı kahverengi ve sonbaharda olgunlaşan türdendirler. Çiçekleri oldukça aromatiktir. Yaprakları hayvan yemi, kağıt hamuru ve tohum posası üretiminde kullanılmaktadır. İğdenin bilinen çok sayıda tıbbi faydası bulunmaktadır. Halk arasında meyve ve çiçekleri tonik ve antipiretik olarak kullanılmaktadır. Daha çok üriner rahatsızlıklarda, gastrik bozukluklarda, diyarede, mide bulantısında, kusmada, sarılıkta ve astım tedavisinde kullanılmaktadır. Son farmakolojik çalışmalar iğde çekirdeğinin antibakteriyel, antienflamatuar, kas gevşetici etkisi olduğu da gösterilmiştir [30].

$\mathrm{Bu}$ çalışmada; $\mathrm{ZnCI}_{2}$ aktifleştiricisi kullanılarak kimyasal aktivasyon yöntemiyle iğde çekirdeğinden elde edilen $1836 \mathrm{~m}^{2} \cdot \mathrm{g}^{-1}$ yüzey alanına sahip aktif karbon kullanılarak sulu çözeltilerden $\mathrm{Pb}$ (II) adsorpsiyonu incelenmiştir.

\section{Materyal ve Metot}

\subsection{Aktif karbon}

Aktif karbon; iğde çekirdeklerinden kimyasal aktivasyon yöntemiyle hazırlanmış olup aktifleştirici olarak $\mathrm{ZnCI}_{2}$ kullanılmıştır (İÇAK). Aktif karbon hazırlanma yöntemi önceki çalışmamızda ayrıntılı biçimde verilmiştir [7]. Hazırlanan aktif karbonun yüzey alanı ( $\mathrm{S}_{\mathrm{BET}}$ ), toplam gözenek hacmi ve ortalama gözenek çapı sırasıyla $1836 \mathrm{~m}^{2} \cdot \mathrm{g}^{-1}, 1,03 \mathrm{cc} \cdot \mathrm{g}^{-1}$ ve $1,53 \mathrm{~nm}$ olarak belirlenmiştir.

\subsection{Kimyasallar}

Deneyde kullanılan kimyasal maddelerin tamamı analitik saflıkta olup Merck-Millipore firmasından temin edilmiştir.

\subsection{Adsorpsiyon çalışmaları}

İÇAK kullanılarak sulu çözeltilerden $\mathrm{Pb}$ (II) adsorpsiyonu işlemi kesikli sistemde gerçekleştirilmiştir. $\mathrm{Pb}$ (II) adsorpsiyonu üzerine, çözelti başlangıç pH'ı, ağır metal başlangıç derişimi, aktif karbon miktarı ve işlem sıcaklığı parametrelerinin etkileri ayrı ayrı incelenmiştir. Adsorpsiyon işleminin ardından çözelti içerisindeki Pb(II) derişimi Atomik Absorpsiyon Spektrometresi (AAS) ( Perkin Elmer AAnalyst 700) ile tespit edilmiştir. Aktif karbonun denge durumunda adsorpladığ $\mathrm{Pb}$ (II) miktarı $\left(\mathrm{q}_{\mathrm{e}}\right)$ ve $\mathrm{Pb}$ (II) giderim yüzdesi (R), Eşitlik 1 ve Eşitlik 2 kullanılarak hesaplanmıştır.

$$
\begin{aligned}
& q_{e}=\frac{\left(C_{0}-C_{e}\right)}{w} V \\
& R=\frac{\left(C_{0}-C_{e}\right)}{C_{0}} 100
\end{aligned}
$$

$\mathrm{C}_{0}$, çözeltideki $\mathrm{Pb}$ (II)'nin başlangıç derişimi (mg. $\mathrm{l}^{-1}$ ); $\mathrm{C}_{\mathrm{e}}$ denge durumunda çözeltideki $\mathrm{Pb}(\mathrm{II})$ derişimi $\left(\mathrm{mg} .1^{-1}\right) ; \mathrm{V}$, çözelti hacmi (ml); w, aktif karbon miktarı $(\mathrm{g}) \mathrm{R}$, giderim yüzdesidir. 


\subsubsection{Adsorpsiyon kinetik çalışmaları}

İÇAK kullanılarak yürütülen sulu çözeltilerden $\mathrm{Pb}(\mathrm{II})$ adsorpsiyonuna ait veriler kullanılarak, adsorpsiyon prosesinin kinetik davranışı aydınlatılmaya çalışılmıştır. $\mathrm{Bu}$ amaçla yalancı birinci dereceden kinetik modeli, yalancı ikinci dereceden kinetik modeli, Elovich modeli ve Partikül içi difüzyon modeli olmak üzere dört farklı kinetik model kullanılmıştır. Lagergen tarafından geliştirilen yalancı birinci dereceden kinetik model [8] ve Ho ve Mckay tarafindan geliştirilen yalancı ikinci dereceden kinetik model eşitliği [9] Eşitlik 3 ve Eşitlik 4'de verilmiştir.

$$
\begin{aligned}
& \ln \left(q_{e}-q_{t}\right)=\ln q_{e}-k_{1} \cdot t \\
& \frac{t}{q_{t}}=\frac{1}{k_{2} q_{m}^{2}}+\frac{1}{q_{m}} t
\end{aligned}
$$

Eşitlik 3 ve Eşitlik 4'de yer alan $\mathrm{k}_{1}$, yalancı birinci dereceden kinetik model sabiti $\left(\mathrm{dk}^{-1}\right) ; \mathrm{k}_{2}$, yalancı ikinci dereceden kinetik model sabiti $\left(\mathrm{g} \cdot \mathrm{mg}^{-1} \cdot \mathrm{dk}^{-1}\right) ; \mathrm{q}, \mathrm{t}$ anında adsorpsiyon kapasitesi $\left(\mathrm{mg} \cdot \mathrm{g}^{-1}\right)$ ve $\mathrm{q}_{\mathrm{m}}$, maksimum adsorpsiyon kapasitesidir $\left(\mathrm{mg} \cdot \mathrm{g}^{-1}\right)$.

Yalancı ikinci dereceden kinetik model sabiti kullanılarak adsorpsiyonun başlangıç hızı(h) Eşitlik 5 ile belirlenir.

$$
\mathrm{h}=k_{2} q_{m}^{2}
$$

Elovich[10] kinetik modeline ait denklem Eşitlik 6'da verildiği gibidir.

$$
q_{t}=\frac{1}{\beta} \ln (\alpha \cdot \beta)+\frac{1}{\beta} \ln t
$$
$\left(\mathrm{g} \cdot \mathrm{g}^{-1}\right)$.

Eşitlik 6'daki $\alpha$ ve $\beta$ sırasıyla başlangıç adsorpsiyon hızı $\left(\mathrm{g}^{-g^{-1}} \cdot \mathrm{dk}^{-1}\right)$ ve desorpsiyon sabitidir Partikül içi difüzyon modeli ile difüzyon katsayısı Eşitlik 7 ile belirlenmektedir [11].

$$
q_{t}=k_{i d} \cdot t^{1 / 2}+C
$$
sabittir(mg. $\left.\mathrm{g}^{-1}\right)$.

$\mathrm{k}_{\mathrm{id}}$ Ve C sırasıyla partikül içi difüzyon hız sabiti $\left(\mathrm{mg} \cdot \mathrm{g}^{-1} \cdot \mathrm{dk} .^{1 / 2}\right)$ ve sınır tabaka kalınlığıyla ilgili

\subsubsection{Adsorpsiyon izoterm çalışmaları}

İÇAK kullanılarak Pb(II) adsorpsiyonuna ait denge değerleri Langmiur, Freundlich, Temkin ve Dubinin-Radushkevich izotermleri kullanılarak incelenmiştir. Langmuir denklemi Eşitlik 8'de verildiği gibidir [12].

$$
\frac{C_{e}}{q_{e}}=\frac{1}{K_{L} q_{\max }}+\frac{C_{e}}{q_{\max }}
$$

Eşitlik 8'de, $\mathrm{q}_{\mathrm{e}}$ denge durumunda adsorpsiyon kapasitesi $\left(\mathrm{mg} \cdot \mathrm{g}^{-1}\right) ; \mathrm{C}_{\mathrm{e}}$ denge durumunda çözelti derişimi (mg. $\left.1^{-1}\right)$; $\mathrm{q}_{\text {maks }}$, birim aktif karbon başına tek tabakada adsorplanan madde miktarı $(\mathrm{mg}(\mathrm{g})$ ve $\mathrm{K}_{\mathrm{L}}$, Langmuir sabitidir $\left(1 . \mathrm{mg}^{-1}\right)$.

Weber ve Chakkravarti tarafından önerilen ayırma sabiti ve parametresi olarak adlandırılan, $R_{L}$, Langmuir izoterminin karakteristlik özelliğini belirlemede kullanılır. $\mathrm{R}_{\mathrm{L}}$ değeri, Eşitlik 9'da verildiği gibi hesaplanmaktadır[13].

$$
R_{L}=\frac{1}{1+K_{L} C_{0}}
$$


Langmuir ayırma faktörü $R_{L}$ seçilen aktif karbonun uygunluğu hakkında fikir vermektedir. $R_{L}>1$ uygun değildir. $\mathrm{R}_{\mathrm{L}}=1$ doğrusal $0<\mathrm{R}_{\mathrm{L}}<1$ uygun, ve $\mathrm{R}_{\mathrm{L}}=0$ tersinmez anlamına gelmektedir.

Freundlich İzotermine ait denklem, Eşitlik 10'da verildiği gibidir [14].

$$
\log q_{e}=\log K_{F}+\frac{1}{n} \log C_{e}
$$

Eşitlik 10 'da de yer alan $\mathrm{K}_{\mathrm{F}}\left(\mathrm{mg}^{1-(1 / \mathrm{n})} 1^{1 / \mathrm{n}} \mathrm{g}^{-1}\right)$ ve $\mathrm{n}$ Freundlich sabitleridir.

Temkin izotermi, Eşitlik 11 ve Eşitlik 12'de verilen denklemler ile ifade edilmektedir [15].

$$
\begin{aligned}
& q_{e}=B \ln A+B \ln C_{e} \\
& B=\frac{R T}{b}
\end{aligned}
$$

Eşitlik 11'de yer alan b, Temkin adsorpsiyon 1sısı sabiti(j.mol $\left.{ }^{-1}\right)$; A, denge bağ sabitidir $\left(1 . \mathrm{g}^{-1}\right)$. Dubinin-Radushkevich (D-R) İzotermi eşitliği Eşitlik 13'de verildiği şekildedir[16].

$$
q_{e}=q_{s} \exp (-B \in)
$$

Eşitlik 13'de, B, D-R izoterm sabiti $\left(\mathrm{kj}^{2} \cdot \mathrm{mol}^{-2}\right) \in$ : Polanyi potansiyelidir.

Polanyi potansiyeli ise, Eşitlik 14 ile belirlenmektedir[17]. Dubinin-Radushkevich izoterm sabiti olan B'nin Eşitlik 15' de kullanılmasıyla adsorpsiyon enerjisi (E)(mol.kj $\left.{ }^{-1}\right)$ hesaplanmaktadır.

$$
\begin{aligned}
& E=R T \ln \left(1+\frac{1}{C_{e}}\right) \\
& E=\frac{1}{\sqrt{2 B}}
\end{aligned}
$$

\section{Sonuçlar ve Tartışma}

\section{1 Çözelti pH'ının Pb(II) adsorpsiyonuna etkisi}

Çözeltinin $\mathrm{pH}$ değeri, ağır metal adsorpsiyonunda önemli bir parametre olup adsorpsiyon üzerinde belirgin bir etkisi vardır. Deneysel çalışmalar $30^{\circ} \mathrm{C}^{\prime} \mathrm{de}, 100 \mathrm{mg} \mathrm{Pb}(\mathrm{II}) / 1$ başlangıç derişimi, $100 \mathrm{ml}$ çözelti hacmi ve 0,1 g aktif karbon miktarı dikkate alınarak 2-5 aralığında değişen çözelti başlangıç pH değerleri için çalkalamalı su banyosunda gerçekleştirilmiştir. Elde edilen veriler Şekil 1' da verilmiştir.

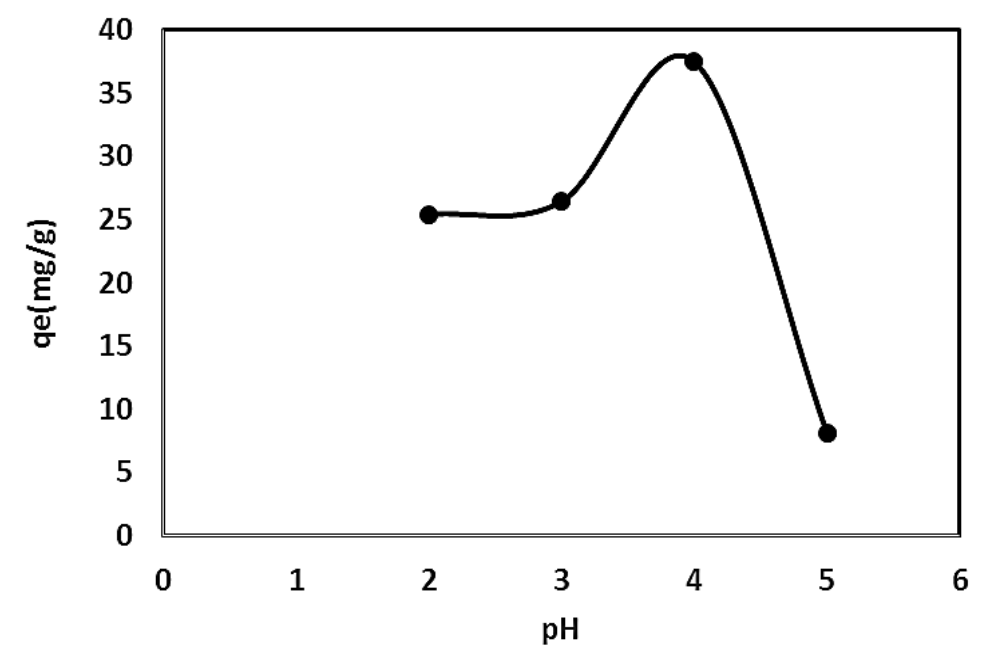

Şekil 1. Çözelti pH'nnın $\mathrm{Pb}(\mathrm{II})$ adsorpsiyon kapasitesine etkisi (T: $30^{\circ} \mathrm{C}$, başlangıç derişimi: $100 \mathrm{mg} . \mathrm{l}^{-1}$ ) 
Şekil 1'de görüldüğü gibi, çözelti pH'sının 2'den $\mathrm{pH}$ 4'e yükselmesi ile adsorpsiyon kapasitesinin arttığı ve $\mathrm{pH} 4$ 'den yüksek değerler için ise düş̧üğü görülmektedir. $\mathrm{pH}<4$ olduğunda adsorpsiyon kapasitesinin düşük olmasının sebepleri; aktif karbon yüzeyinin protonlaşması ve çözelti ortamında bulunan $\mathrm{H}^{+}$iyonlarının aktif karbonun aktif merkezlerine bağlanmak için $\mathrm{Pb}$ (II) iyonları ile rekabet etmesi olduğu düşünülmektedir [18]. Artan pH ile birlikte adsorpsiyon kapasitesinin artmasının sebebinin ise; aktif karbon yüzeyindeki negatif grupların artması ve aktif karbonun aktif merkezlerine bağlanmak için $\mathrm{Pb}$ (II) iyonları ile yarışacak $\mathrm{H}^{+}$iyon sayısının azalması olduğunu söylemek mümkündür [19]. Çözelti pH'ının 5'den yüksek değerleri için, çözeltideki $\mathrm{Pb}(\mathrm{II})$ iyonlarının $\mathrm{Pb}(\mathrm{OH})_{2}$ şeklinde çökmesi sebebiyle yüksek pH değerleri çalışılamamıştır.

$\mathrm{Pb}(\mathrm{II})$ 'in adsorpsiyonu ile ilgili diğer parametrelerin incelenmesinde çözeltinin başlangıç $\mathrm{pH}$ değerinin 4 olarak seçilmesinin uygun olduğu sonucuna varılmıştır.

\subsection{Aktif karbon miktarının Pb(II) adsorpsiyonuna etkisi}

Çalışmanın bu basamağında aktif karbon miktarının $\mathrm{Pb}$ (II) adsorpsiyonuna etkisi incelenmiştir. Deneysel çalışmalar, çözelti başlangıç pH değeri 4, çözelti başlangıç derişimi $100 \mathrm{mg} . \mathrm{l}^{-1}, 100 \mathrm{ml}$ çözelti hacmi ve $30^{\circ} \mathrm{C}$ çözelti sıcaklığ 1 dikkate alınarak gerçekleştirilmiştir. Kullanılan aktif karbon miktarları $0,025,0,05,0,1,0,15,0,2$ ve $0,3 \mathrm{~g}$ olup adsorpsiyon kapasitesi ve giderim yüzdesi (\%R)'nin aktif karbon miktarı ile değişimi Şekil 2' de verilmiştir.

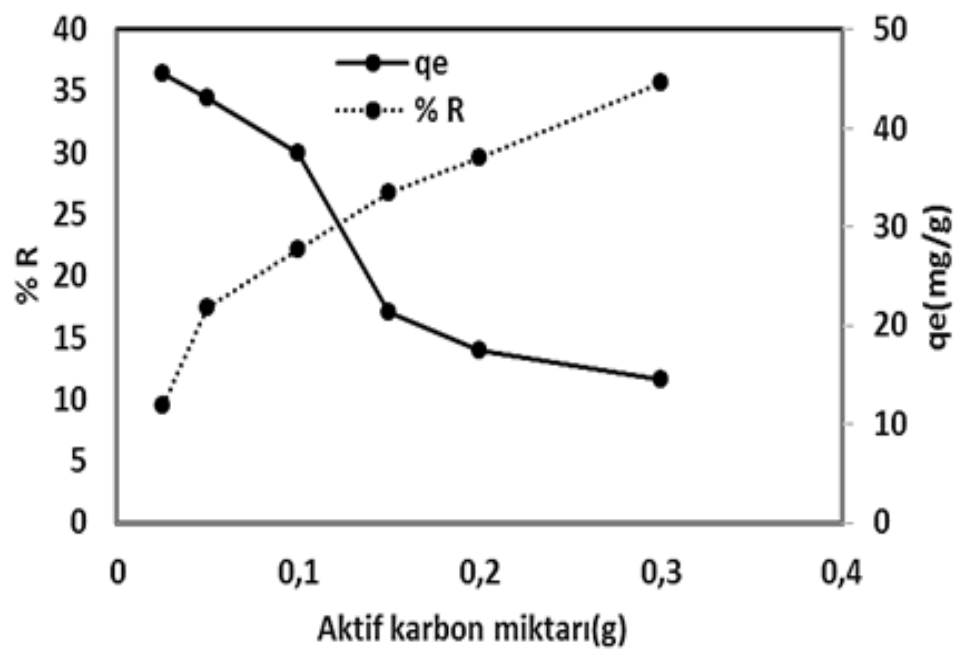

Şekil 2. Aktif karbon miktarının adsorpsiyona etkisi (T: $30^{\circ} \mathrm{C}$, başlangıç derişimi: $100 \mathrm{mg} .1^{-1}$ )

Şekil 2'de görüldüğü gibi, aktif karbon miktarının artması ile $\mathrm{Pb}(\mathrm{II})$ giderim yüzdesinin(R) arttığ1 görülmektedir. Bu durumun nedeni; aktif karbon miktarının artmasıyla hem aktif karbon yüzey alanın artması hem de uygun ve kullanılabilir aktif merkez sayısının artmasıdır [20]. Aktif karbon miktarının artmasıyla adsorpsiyon kapasitesi ise azalmaktadır. Bu durumun nedeni ise; artan aktif karbon miktarı ile kullanılabilir aktif merkezlerin sayısının artması ve bu merkezlerin dolmasına yetecek kadar $\mathrm{Pb}(\mathrm{II})$ iyonlarının bulunmamasidır [21].

\section{3. Çözelti başlangıç derişiminin $\mathrm{Pb}(\mathrm{II})$ adsorpsiyonuna etkisi}

Farklı başlangıç derişimleri için $\mathrm{Pb}(\mathrm{II})$ adsorpsiyon kapasitesi belirlenmiştir. Çözelti başlangıç derişimi $50,100,150,250$ ve $500 \mathrm{mg} . \mathrm{l}^{-1}$ olarak çalışılmıştır. Deneysel çalışmalar, $30^{\circ} \mathrm{C}$ çözelti ortam sicaklığı, $100 \mathrm{ml}$ çözelti hacmi, 0,1g aktif karbon miktarı ve çözelti pH değeri 4 alınarak gerçekleştirilmiştir. Giderim yüzdesinin (R) işlem zamanı ile değişimi Şekil 3a' da verildiği şekildedir. Çözelti başlangıç derişimi, adsorpsiyon kapasitesi ve giderim yüzdesi (R) arasındaki değişim ise Şekil 3b' de verilmiştir. 


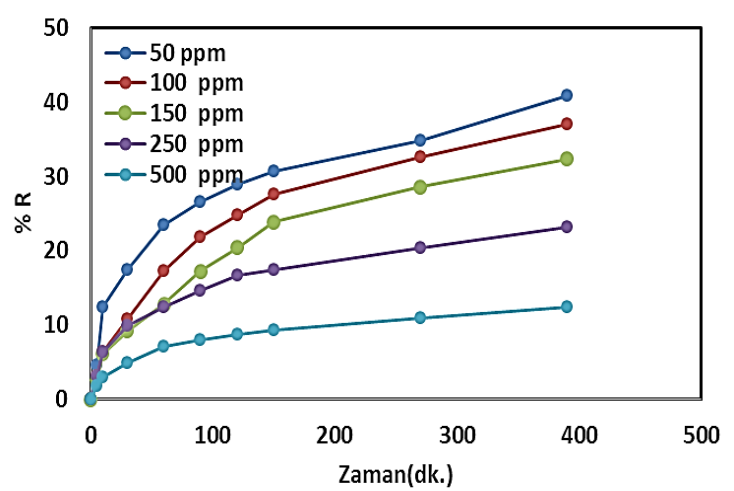

a

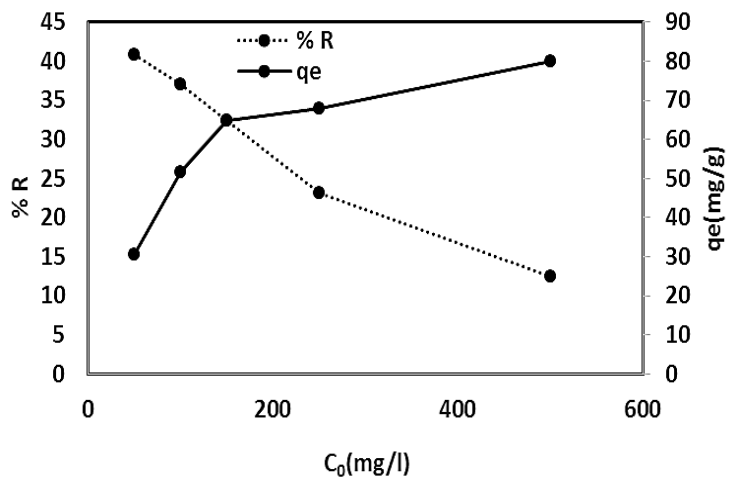

$\mathrm{b}$

Şekil 3. a-) Çözelti başlangıç derișiminin \% giderimin zaman ile değișimi

b-) Çözelti başlangıç derişiminin \% giderim ve adsorpsiyon kapasitesinin başlangıç konsantrasyonu ile değişim (T: $303 \mathrm{~K}$, aktif karbon miktarı: $0.1 \mathrm{~g}$ )

Şekil 3a'da görüldüğü gibi, işlem süresi uzadıkça, uzaklaştırılan $\mathrm{Pb}(\mathrm{II})$ miktarı da artmaktadır. Adsorpsiyonun başlangıç aşamasında yüksek oranda $\mathrm{Pb}(\mathrm{II})$ giderimi gerçekleşmekte ve sonrasında bir yavaşlama olduğu da görülmektedir. Bu durumun sebebi, işlem başlangıcında aktif karbon yüzeyinde bulunan çok sayıdaki boş aktif merkezlerin (gözenek içi dahil) işgal edilmemesidir. Bunun sonucunda da adsorpsiyon hızlı bir şekilde gerçekleşmektedir. İlerleyen zamanla, kullanılabilir boş aktif merkezlerin sayısının azalmasıyla adsopsiyon hızı da azalmaktadır [22]. Şekil 3 a ve b'den, çözelti derişiminin artması ile $\mathrm{Pb}(\mathrm{II})$ giderim yüzdesinin (R) azaldığı görülmektedir. Bu durumun sebepleri; aktif karbon yüzeyindeki aktif merkezlerin sınırlı olması ve adsorbat molekülleri arasındaki rekabetin artmasıdır [23]. Şekil 3b'den görüldüğü gibi, çözelti başlangıç derişimi arttıkça adsorpsiyon kapasitesi de artmaktadır. Bu durumun sebepleri; çözelti başlangıç derişiminin artmasıyla sıvı faz ile katı faz arasında aşırı güçlü bir kütle transfer direncin oluşması ve yüksek derişimlerde kütle transferi itici gücünün çok daha etkin olmasıdır [24].

\section{4. Çözelti sıcaklığının $\mathrm{Pb}(\mathrm{II})$ adsorpsiyonuna etkisi}

$\mathrm{Pb}$ (II) adsorpsiyon kapasitesi üzerine çözelti sıcaklığının etkisi, 20, 30, 40 ve $50^{\circ} \mathrm{C}$ işlem sıcaklıkları için incelenmiştir. Deneysel çalışma; çözelti başlangıç pH'1 4, aktif karbon miktarı 0,1g, çözelti başlangıç derişimi 100 ppm ve çözelti hacmi $100 \mathrm{ml}$ alınarak gerçekleştirilmiştir. İşlem sıcaklığı ile $\mathrm{Pb}(\mathrm{II})$ adsorpsiyon kapasitesinin zamana bağlı değişimi Şekil 4a' da verildiği gibidir.

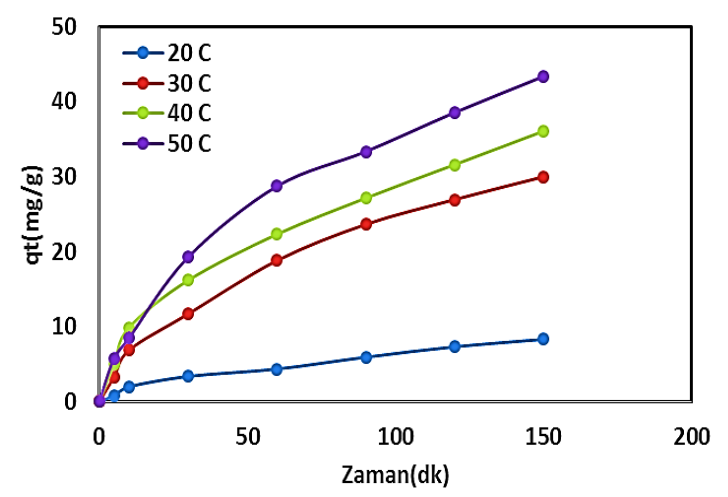

a

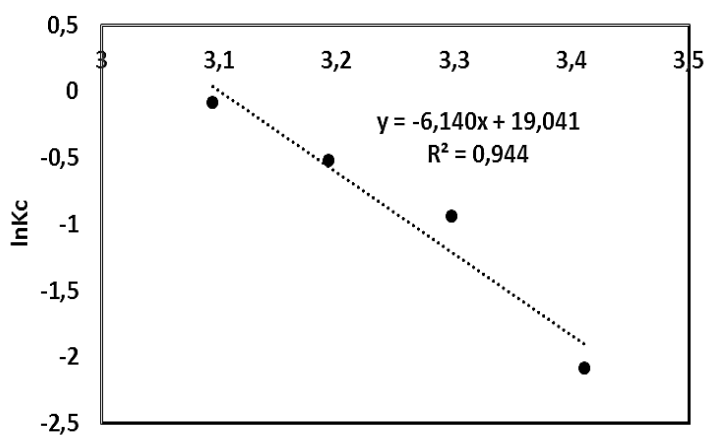

b

Şekil 4.a-) İşlem Sıcaklığının $\mathrm{Pb}(\mathrm{II})$ adsorpsiyonu üzerine etkisi

b-) $\ln \mathrm{K}_{\mathrm{c}}-1 / \mathrm{T}$ grafiği (A- The effect of temperature on $\mathrm{Pb}$ (II) adsorption $\mathrm{B}-\ln \mathrm{K}_{\mathrm{c}}-1 / \mathrm{T}$ chart)

Şekil 4a'dan görüldüğü gibi, işlem sıcaklığının artması ile birlikte adsorpsiyon kapasitesi de artmaktadır. Adsorpsiyon kapasitesinin sıcaklıkla artması adsorpsiyon işleminin endotermik karakterde olduğunu göstermektedir [25]. Artan sıcaklıkla adsorpsiyon kapasitesinin artmasının sebepleri; artan 
sıcaklıkla $\mathrm{Pb}$ (II) iyonlarının difüzyon hızının artması ve $\mathrm{Pb}$ (II) moleküllerinin hareketliliğinin artması sonucunda yüzey üzerindeki aktif merkezler ile daha çok etkileşmenin ortaya çımasıdır [26].

\subsection{Adsorpsiyon kinetik modelinin belirlenmesi}

Kinetik modeller adsorpsiyon prosesinin hızını belirlemek için kullanılırlar. Çalışmanın bu basamağında, aktif karbon kullanılarak (işlem sıcaklığı $30^{\circ} \mathrm{C}$, çözelti başlangıç derişimi 100 ppm) yürütülen $\mathrm{Pb}(\mathrm{II})$ adsorpsiyonuna ait denge verileri kullanılarak, adsorpsiyon prosesinin kinetik davranış1 aydınlatılmaya çalışılmıştır. İncelenen adsorpsiyon kinetik modellerine ait grafikler Şekil 5'de ve hesaplanan kinetik sabitler ise Tablo 1'de verilmiştir.

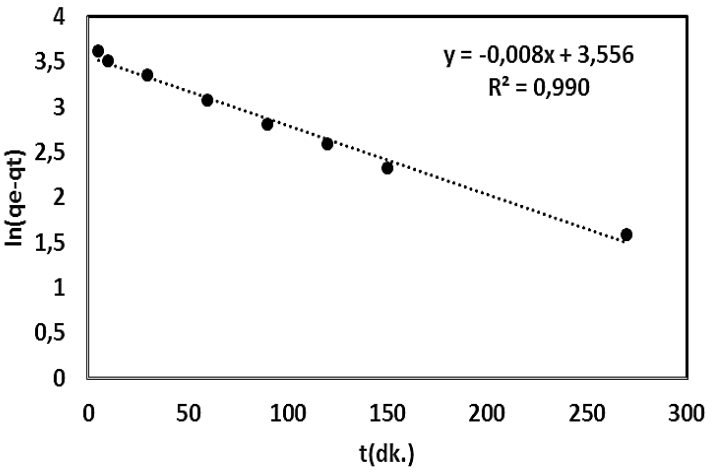

a

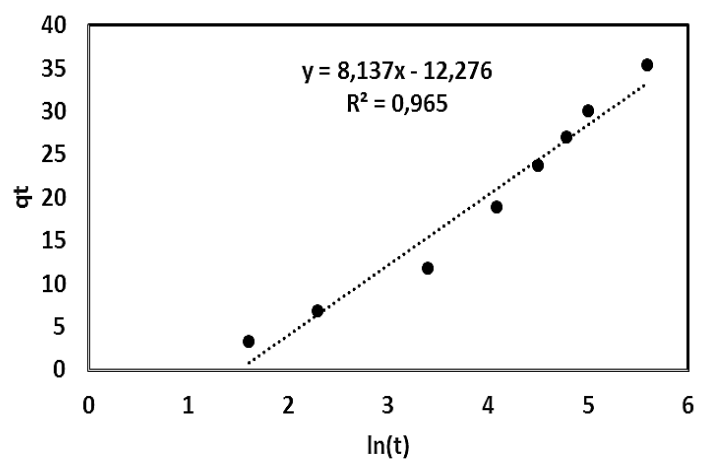

c

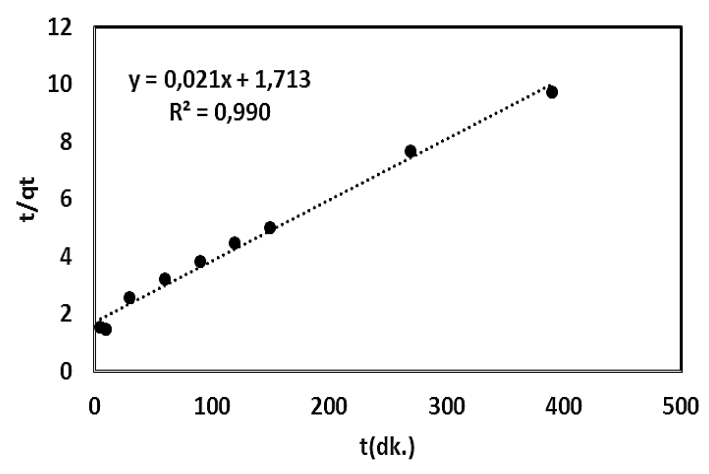

b

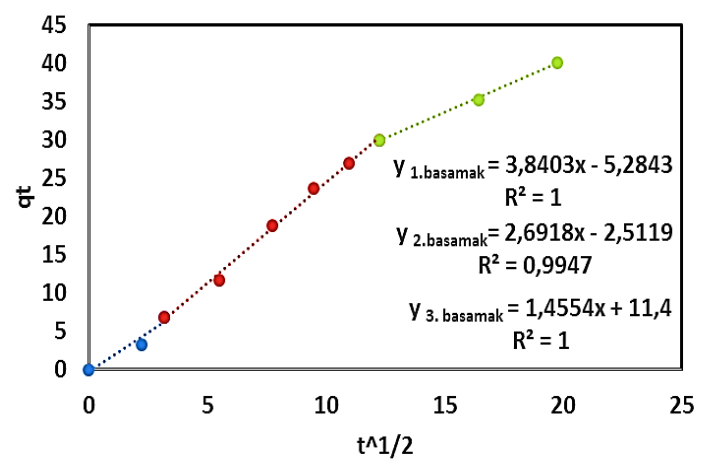

$\mathrm{d}$

Şekil 5. $\mathrm{Pb}(\mathrm{II})$ adsorpsiyonuna ait kinetik modellerin grafikleri

a-) yalancı birinci dereceden; b-)yalancı ikinci dereceden; c-) Elovich; D-)Partikül içi difüzyon (Pb(II)derişimi: 100 mg.L ${ }^{-1}$, aktif karbon miktarı: 0.1,)

Şekil 5d'de verilen Partikül İçi Difüzyon Modeline ait grafiğin birden fazla lineer doğrudan oluşması difüzyonun üç basamakta gerçekleştiğine işaret etmektedir [27]. Birinci basamak, çok kısadır ve dış difüzyon kontrollüdür. İkinci basamak, kompleks bir adsorpsiyon basamağı olup partikül içi difüzyon kontrollüdür. Üçüncü basamak, adsorpsiyon prosesinin dengeye geldiği basamak olup partikül içi difüzyon yavaşlamaktadır. Tablo 1'den görüleceği gibi, her bir basamağın difüzyon katsayısı dikkate alındığında, difüzyon katsayısı en küçük $(1,455)$ olan 3 . basamağın kontrol basamağı olduğu görülmektedir. Tablo 1'den, partikül içi difüzyon sabitinin (C) küçük olmadığı da görülmektedir. Bu durum, aktif karbonun dış adsorpsiyon tabakasının kalın olduğuna işaret etmektedir [10].

Tablo 1'den görüldüğü gibi, yalancı ikinci dereceden kinetik modele ait regresyon katsayıs1 daha büyük olmasına rağmen, Elovich kinetik modelin standart sapması daha küçük olması sebebiyle, $\mathrm{Pb}(\mathrm{II})$ adsorpsiyon kinetiğinin Elovich kinetik modeli ile ifade edilmesinin uygun olacağına karar verilmiştir. Elovich kinetik modele göre aktif karbon desorpsiyon kapasitesi ( $\beta$ ) $0,123 \mathrm{mg} \cdot \mathrm{g}^{-1}$ olarak hesaplanmıştır. 
Tablo 1. $\mathrm{Pb}(\mathrm{II})$ adsorpsiyonuna ait kinetik sabitler (The kinetic constants of $\mathrm{Pb}$ (II) adsorption)

\begin{tabular}{|c|c|c|c|c|c|}
\hline \multicolumn{6}{|c|}{ Yalancı birinci dereceden kinetik modeli } \\
\hline $\mathbf{k}_{1}\left(\mathbf{d k}^{-1}\right)$ & $\mathbf{R}^{2}$ & $\Delta \mathbf{q}(\%)$ & & & \\
\hline 0,00765 & 0,989 & 3,672 & & & \\
\hline \multicolumn{6}{|c|}{ Yalancı ikinci dereceden kinetik modeli } \\
\hline $\mathrm{k}_{2}\left(\mathrm{~L}_{\mathbf{m}} \mathrm{mg}^{-1} \cdot \mathbf{d k} \cdot^{-1}\right)$ & $\mathbf{R}^{2}$ & $\mathbf{h}$ & $\Delta \mathbf{q}(\%)$ & & \\
\hline 46,948 & 0,990 & 0,584 & 4,894 & & \\
\hline \multicolumn{6}{|l|}{ Elovich Modeli } \\
\hline$\alpha$ & $\boldsymbol{\beta}$ & $\mathbf{R}^{2}$ & $\Delta \mathbf{q}(\%)$ & & \\
\hline 1,799 & 0,123 & 0,965 & 1,666 & & \\
\hline \multicolumn{6}{|c|}{ Partikül içi difüzyon modeli } \\
\hline $\mathrm{k}_{\mathrm{id}, 1}\left(\mathrm{mg} \cdot \mathrm{g}^{-1} \cdot \mathrm{dk} \cdot \cdot^{-1 / 2}\right)$ & $\mathrm{kid}_{\mathbf{2}, 2}\left(\mathrm{mg} \cdot \mathrm{g}^{-1} \cdot \mathrm{dk}^{-1 / 2}\right)$ & $\mathrm{k}_{\mathrm{id}, 3}\left(\mathrm{mg}_{\mathrm{g}} \mathrm{g}^{-1} \cdot \mathrm{dk} .^{-1 / 2}\right)$ & $\mathbf{C}$ & $\mathbf{R}^{2}$ & $\Delta \mathbf{q}(\%)$ \\
\hline 3,840 & 2,692 & 1,455 & 7,85 & 0,867 & 4,007 \\
\hline
\end{tabular}

\section{6. $\mathrm{Pb}(\mathrm{II})$ adsorpsiyon izotermlerinin türetilmesi}

Çalışmanın bu basamağında $50 \mathrm{mg} . \mathrm{l}^{-1}, 100 \mathrm{mg} . \mathrm{l}^{-1}, 150 \mathrm{mg} \cdot \mathrm{l}^{-1}, 250 \mathrm{mg} \cdot \mathrm{l}^{-1}$ ve $500 \mathrm{mg} . \mathrm{l}^{-1}$ olmak üzere farklı başlangıç derişimlerine sahip $\mathrm{Pb}(\mathrm{II})$ çözeltilerinin adsorpsiyonlarına ait denge değerleri Langmiur, Freundlich, Temkin ve Dubinin-Radushkevich izotermleri kullanılarak incelenmiştir (Şekil 6).

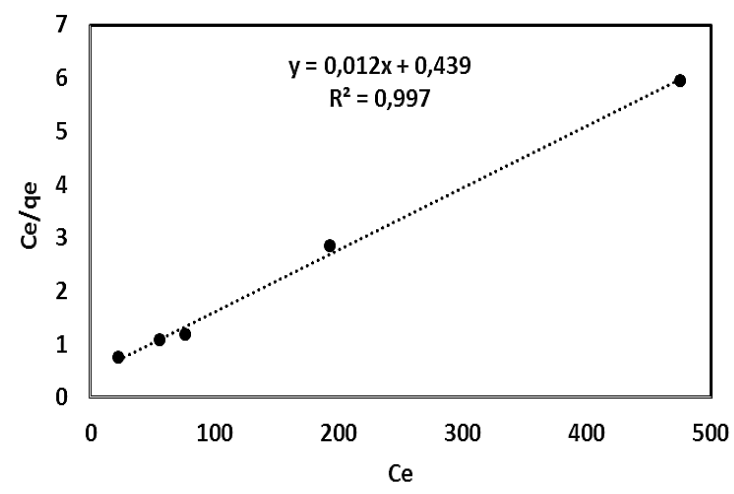

a

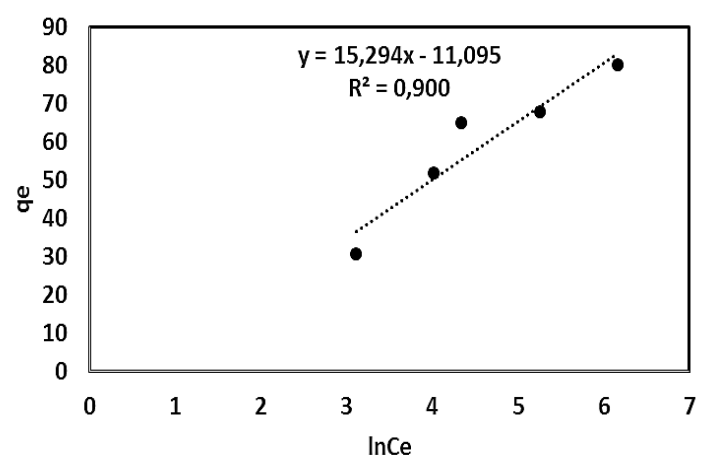

c

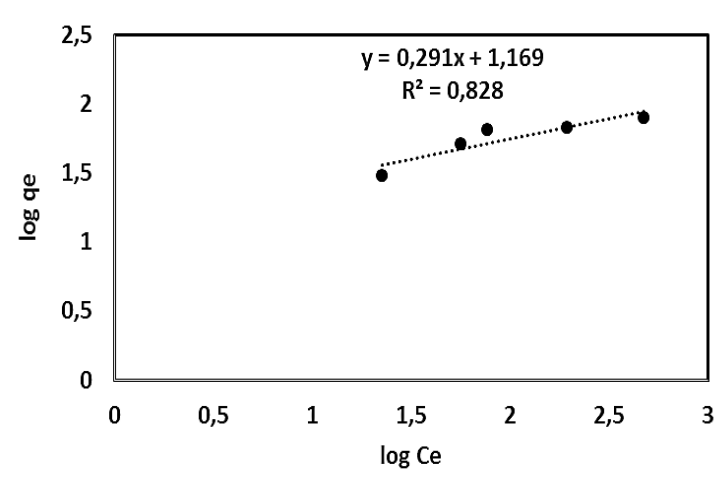

b

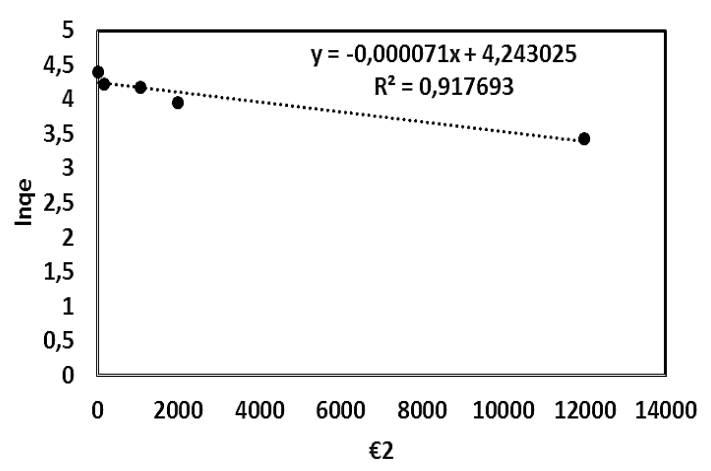

d

Şekil 6. $\mathrm{Pb}(\mathrm{II})$ adsorpsiyon izoterm grafikleri(T: $30^{\circ} \mathrm{C}$, aktif karbon miktarı: $0,1 \mathrm{~g}$ ) a-)Langmuir; b-) Freundlich; c-)Temkin; d-)D-R (Pb (II) adsorption isotherm charts) 
Şekil 6'da verilen izoterm modellerine ait denklemler kullanılarak $\mathrm{Pb}(\mathrm{II})$ adsorpsiyonu için izoterm sabitleri ve izotermlere ait korelasyon katsayıları hesaplanmıştır (Tablo 2).

Tablo 2. $\mathrm{Pb}$ (II) Adsorpsiyon izoterm modellerine ait izoterm sabitleri(The isotherm constants of the adsorption isotherm models for $\mathrm{Pb}$ (II) adsorption)

\begin{tabular}{|c|c|c|}
\hline $\begin{array}{c}\mathbf{q}_{\max }\left(\mathbf{m g . g} \mathbf{g}^{-1}\right) \\
86,207\end{array}$ & $\begin{array}{c}\text { Langmuir } \\
\mathbf{K}_{\mathbf{L}} \\
0,0264 \\
\end{array}$ & $\begin{array}{c}\mathbf{R}^{2} \\
0,997\end{array}$ \\
\hline $\begin{array}{c}\mathbf{K}_{\mathbf{f}}\left(\mathbf{m g} \cdot \mathbf{g}^{-\mathbf{1}}\right)\left(\mathbf{m g} \cdot \mathbf{L}^{-\mathbf{1}}\right)^{\mathbf{1} / \mathbf{n}} \\
14,754\end{array}$ & $\begin{array}{c}\text { Freundlich } \\
\mathbf{n} \\
3,432\end{array}$ & $\begin{array}{c}\mathbf{R}^{2} \\
0,823\end{array}$ \\
\hline $\begin{array}{c}\mathbf{K}_{\mathbf{t}}\left(\mathbf{L}_{\mathbf{L}} \mathbf{g}^{-\mathbf{1}}\right) \\
0,484\end{array}$ & $\begin{array}{c}\text { Temkin } \\
\mathbf{b}\left(\mathbf{J}^{\prime} \mathbf{m o l}^{-1}\right) \\
164,796\end{array}$ & $\begin{array}{c}\mathbf{R}^{2} \\
0,900\end{array}$ \\
\hline $\begin{array}{c}\mathbf{q m}_{\mathbf{m}}\left(\mathbf{m g . g}^{-\mathbf{1}}\right) \\
69,616\end{array}$ & $\begin{array}{c}\text { Dubinin-Radushkevich(D-R) } \\
\text { E }\left(\mathbf{k J J}^{-\mathbf{m o l}} \mathbf{1}^{\mathbf{1}}\right) \\
0,845\end{array}$ & $\begin{array}{c}\mathbf{R}^{2} \\
0,918\end{array}$ \\
\hline
\end{tabular}

Tablo 2'den görüldüğü gibi, $\mathrm{Pb}(\mathrm{II})$ adsorpsiyonu için en yüksek regresyon katsayıs1 $\left(\mathrm{R}^{2}=0,997\right)$ Langmuir izoterm modelinde elde edilmiştir. Bu sonuç, adsorpsiyon denge verilerinin Langmuir izotermi ile uyum içerisinde olduğunu göstermektedir. Langmuir adsorpsiyon izoterm modeli; aktif karbon yüzeyinin eş özelliklere sahip boş aktif merkezlerden oluştuğunu, yüzey enerjisinin homojen şekilde dağıldığını kabul etmektedir [28]. Tablo 2'den görüleceği gibi Langmuir izotermine göre tek tabakada maksimum adsorpsiyon kapasitesi $\left(\mathrm{q}_{\text {maks }}\right) 86,207 \mathrm{mg} \cdot \mathrm{g}^{-1}$ olarak bulunmuştur.

Freundlich izoterm sabiti n, 3,432 olarak bulunmuştur. $1 / \mathrm{n}<1$ ise denge verilerinin Langmuir izotermine uyduğu ve birin üstünde ise diğer izotermler ile birlikte değerlendirilmesi gerektiği kabul edilmektedir [29]. 1/n değeri birin altındadır. $\mathrm{Bu}$ sonuç $\mathrm{Pb}$ (II) adsorpsiyonunun Langmuir izotermi ile tanımlanmasının uygun olduğunu desteklemektedir. $\mathrm{Pb}(\mathrm{II})$ adsorpsiyonu denge verilerine DubininRadushkevich izotermi uygulanarak adsorpsiyonun enerjisi (E) $0,845 \mathrm{~kJ} \mathrm{~mol}^{-1}$ olarak belirlenmiştir. $\mathrm{Pb}(\mathrm{II})$ adsorpsiyonu için hesaplanan adsorpsiyon enerjisi fiziksel adsorpsiyona işaret etmektedir.

Langmuir adsorpsiyon izoterminin temel karakteristiği olan ayırma faktörü $\left(\mathrm{R}_{\mathrm{L}}\right)$ değeri de hesaplanmıştır. Farklı başlangıç derişimleri için elde edilen $R_{L}$ değerleri Tablo 3'de verilmiştir. $R_{L}$ değerinin 0 ile 1 arasında olması, hazırlanan aktif karbonun $\mathrm{Pb}(\mathrm{II})$ adsorpsiyon işlemi için uygun olduğunu göstermektedir.

Tablo 3. Langmuir Ayırma faktörü, $\left(\mathrm{R}_{\mathrm{L}}\right)\left(\right.$ Langmuir separation factor, $\mathrm{R}_{\mathrm{L}}$ )

\begin{tabular}{cc}
\hline Derişim $\left(\mathbf{m g . l}^{-1}\right)$ & $\mathrm{R}_{\mathrm{L}}$ \\
\hline 50 & 0,410 \\
100 & 0,262 \\
150 & 0,205 \\
250 & 0,124 \\
500 & 0,064 \\
\hline
\end{tabular}

$\mathrm{Pb}(\mathrm{II})$ adsorpsiyon denge verilerinin Langmuir izotermine uygulanması ile elde edilen tek tabakada adsorpsiyon kapasitesi ve literatürdeki tek tabakadaki adsorpsiyon kapasitesi sonuçları Tablo 4'da verildiği gibidir. 
Tablo 4. $\mathrm{Pb}(\mathrm{II})$ adsorpsiyon sonuçlarının ve literatür sonuçları ile karşılaştırılması

\begin{tabular}{|l|l|l|}
\hline $\mathbf{q}_{\max }(\mathbf{m g} / \mathbf{g})$ & Adsorbent çesidi & Kaynak \\
\hline 21.38 & Aktif karbon & {$[19]$} \\
\hline 0.410 & Aktif karbon & {$[31]$} \\
\hline 23.8 & Biyokütle & {$[20]$} \\
\hline 56.6 & Kompozit & {$[20]$} \\
\hline 163.93 & Biyokütle & {$[32]$} \\
\hline 294.11 & Aktif karbon & {$[33]$} \\
\hline 86.21 & Aktif karbon & Bu çalışma \\
\hline
\end{tabular}

Tablo 4'de $\mathrm{Pb}$ (II) adsorpsiyonunda elde edilen tek tabakadaki adsorpsiyon kapasitesinin yüksek olduğu görülmektedir. Bu sonuç İÇAK aktif karbonun $\mathrm{Pb}(\mathrm{II})$ adsorpsiyonunda kullanılabileceğini göstermektedir.

\section{Sonuçlar}

Aktif karbon kullanılarak gerçekleştirilen $\mathrm{Pb}(\mathrm{II})$ adsorpsiyonu işlemi için en yüksek adsorpsiyon kapasitesi, çözelti başlangıç pH'ının 4 olması durumunda elde edilmiştir. Artan çözelti başlangıç derişimi ile birlikte $\mathrm{Pb}$ (II) uzaklaştırma yüzdesinin azaldığ 1 ve adsorpsiyon kapasitesinin ise arttığı tespit edilmiştir. Ayrıca, artan aktif karbon miktarı ile adsorpsiyon kapasitesinin azaldığı ve $\mathrm{Pb}$ (II) giderim yüzdesinin(R) arttığı da belirlenmiştir. Artan sıcaklık ile birlikte adsorpsiyon kapasitesinin arttığı, $\mathrm{Pb}$ (II) adsorpsiyonunun endotermik olarak gerçekleştiği belirlenmiştir. Adsorpsiyon kinetiğinin Elovich kinetik model ile temsil edilmesinin uygun olacağına karar verilmiştir. Difüzyonu kontrol eden basamak ve difüzyon katsayısı sırasıyla 3. Basamak ve 1,455 olarak belirlenmiştir. Elde edilen adsorpsiyon denge değerlerinin en iyi Langmuir izotermine uyduğu tespit edilmiştir. Langmuir izotermine göre tek tabakada adsorpsiyon kapasitesi 86,207 mg/g olarak hesaplanmıştır. Aktif karbonun $\mathrm{Pb}$ (II) adsorpsiyonu işleminde kullanılabilir yapıda olduğu da belirlenmiştir.

\section{Teșekkür}

Bu çalışma, Selçuk Üniversitesi BAP Koordinatörlügü(Proje No: 13101006) tarafından desteklenmiştir.

\section{Kaynaklar}

[1] Demirbas A. 2008. Heavy metal adsorption onto agro-based waste materials, A review. Journal of Hazardous Materials, 157: 220-229.

[2] Hua M., Zhang S., Pan B., Zhang W., Lv L., Zhang Q. 2012. Heavy metal removal from water/wastewater by nanosized metal oxides, A review. Journal of Hazardous Materials, 211: 317331.

[3] Fu F., Wang Q. 2011. Removal of heavy metal ions from wastewaters, A review. Journal of Environmental Management, 92: 407-418.

[4] İmamoğlu M., Tekir O. 2008. Removal of copper (II) and lead (II) ions from aqueous solutions by adsorption on activated carbon from a new precursor hazelnut husks, Desalination, 228: 108-113.

[5] Saka C., Sahin Ö., Küçük M.M. 2012. Application of agricultural and forest waste adsorbents for removal of lead (II) from contaminated water, International Journal of Environmental Science and Technology, 9: 379-394.

[6] Ceyhan A.A., Şahin Ö., Baytar O., Saka C. 2013. Surface and porous characterization of activated carbon prepared from pyrolysis of biomass by two-stage procedure at low activation temperature and it's the adsorption of iodine, Journal of Analytical and Applied Pyrolysis, 104: 378-383.

[7] Sahin Ö., Saka C., Ceyhan A.A., Baytar O. 2015. Preparation of High Surface Area Activated Carbon from Elaeagnus angustifolia Seeds by Chemical Activation with $\mathrm{ZnCl}_{2}$ in One-Step Treatment and its Iodine Adsorption, Separation Science and Technology, 50: 886-891.

[8] Lagergren S., Svenska, B.K. 1898. Zur Theorie der Sogenannten Adsorption Geloester Stoffe, Vetenskapsakad, Handl, 24: 1-39.

[9] Ho Y.S., McKay G. 2000. The kinetics of sorption of divalent metal ions onto sphagnum moss peat, Water Research, 34 (3): 735-742. 
[10] Cagnon B., Chedeville O., Cherrier, J.F., Caqueret V., Porte C. 2011. Evolution of adsorption kinetics and isotherms of gallic acid on an activated carbon oxidized by ozone: Comparison to the raw material, Journal of the Taiwan Institute of Chemical Engineers, 42 (6): 996-1003.

[11] Weber W.J., Morris J.C. 1963. Kinetics of adsorption on carbon from solution, J. Sanitary Eng. Div, 89 (2): 31-60.

[12] Langmuir I. 1918. The adsorption of gases on plane surfaces of glass, mica and platinum, J. Am. Chem. Soc, 40: 1361-1368.

[13] Weber T.W. 1974. Chakkravorti, R.K., Pore and solid diffusion models for fixedbed adsorbers, AIChE J., 20: 228-238.

[14] Freundlich H.M.F. 1906. Over the adsorption in solution, J. Phys. Chem, 57: 385-470.

[15] Temkin M.I., Pyzhev V. 1940. Kinetics of ammonia synthesis on promoted iron catalyst, Acta Physiochim, 12: 327-356.

[16] De Luna M.D.G., Flores E.D., Genuino D.A.D., Futalan C.M., Wan M.W. 2013. Adsorption of Eriochrome Black T (EBT) dye using activated carbon prepared from waste rice hullsOptimization, isotherm and kinetic studies, Journal of the Taiwan Institute of Chemical Engineers, 44 (4): 646-653.

[17] Kumar K.V., Porkodi K., Rocha F., 2008. Isotherms and thermodynamics by linear and non-linear regression analysis for the sorption of methylene blue onto activated carbon: comparison of various error functions, J Hazard Mater, 151: 794.

[18] Tan I.W., Ahmad L., Hameed B.H. 2008. Adsorption of basic dye on high-surface-area activated carbon prepared from coconut husk: Equilibrium, kinetic and thermodynamic studies, Journal of Hazardous Materials, 154 (1-3): 337-346.

[19] Mouni L., Merabet D., Bouzaza A., Belkhiri L. 2011. Adsorption of Pb(II) from aqueous solutions using activated carbon developed from Apricot stone. Desalination, 276 (1-3): 148-153.

[20] Hamza I.A.A., Martincigh B.S., Ngila J.C. 2013. Nyamori, V.O., Adsorption studies of aqueous $\mathrm{Pb}$ (II) onto a sugarcane bagasse/multi-walled carbon nanotube composite, Physics and Chemistry of the Earth, 66: 157-166.

[21] Nam S.W., Choi D.J., Kim S.K., Her N., Zoh K.D. 2014. Adsorption characteristics of selected hydrophilic and hydrophobic micropollutants in water using activated carbon, Journal of hazardous materials, 270: 144-152.

[22] Noorimotlagh Z., Darvishi Cheshmeh Soltani R., Khataee R., Shahriyar S., Nourmoradi H. 2014. Adsorption of a textile dye in aqueous phase using mesoporous activated carbon prepared from Iranian milk vetch, Journal of the Taiwan Institute of Chemical Engineers, 45 (4): 1783-1791.

[23] Karaçetin G., Sivrikaya S., Imamoğlu M. 2014. Adsorption of methylene blue from aqueous solutions by activated carbon prepared from hazelnut husk using zinc chloride, Journal of Analytical and Applied Pyrolysis, 110: 270-276.

[24] Martín-González M., González-Díaz O., Susial P., Araña J., Herrera-Melián J.A., Doña-Rodríguez J.M., Pérez-Peña J. 2014. Reuse of Phoenix canariensis palm frond mulch as biosorbent and as precursor of activated carbons for the adsorption of Imazalil in aqueous phase, Chemical Engineering Journal, 245: 348-358.

[25] Liu T., Li Y., Du Q., Sun J., Jiao Y., Yang G., Wu D. 2012. Adsorption of methylene blue from aqueous solution by graphene, Colloids and Surfaces B: Biointerfaces, 90 (1): 197-203.

[26] Peydayesh M., Rahbar-Kelishami A. 2014. Adsorption of methylene blue onto Platanus orientalis leaf powder: Kinetic, equilibrium and thermodynamic studies, Journal of Industrial and Engineering Chemistry, 21: 1014-1019.

[27] Ahmed M.J., Dhedan S.K. 2012. Equilibrium isotherms and kinetics modeling of methylene blue adsorption on agricultural wastes-based activated carbons, Fluid Phase Equilibria, 317: 9-14.

[28] Hameed B.H., El-Khaiary M.I. 2008. Batch removal of malachite green from aqueous solutions by adsorption on oil palm trunk fibre: Equilibrium isotherms and kinetic studies, Journal of Hazardous Materials, 154 (1-3): 237-244.

[29] Liu Q.S., Zheng T., Wang P., Guo L. 2010. Preparation and characterization of activated carbon from bamboo by microwave-induced phosphoric acid activation, Industrial Crops and Products, 31 (2): 233-238. 
[30] Yalçın G. 2012. İğde (Elaeagnus angustifolia L.) Bitkisinin Çesitli Kısımlarının Kimyasal Bilesenlerinin Farklı Yöntemler Kullanılarak Antioksidan Kapasitesinin İncelenmesi, Doktora Tezi, Ege Üniversitesi Sağllk Bilimleri Enstitüsü, İzmir.

[31] Sreejalekshmi, K.G., Krishnan, K.A., Anirudhan, T.S., 2009. Adsorption of Pb(II) and Pb(II)-citric acid on sawdust activated carbon: Kinetic and equilibrium isotherm studies. Journal of Hazardous Materials, 161 (2-3): 1506-1513.

[32] Sun S., Yang J., Li Y., Wang K., Li X., 2014. Ecotoxicology and Environmental Safety Optimizing adsorption of $\mathrm{Pb}$ ( II ) by modi fi ed litchi pericarp using the response surface methodology. Ecotoxicology and Environmental Safety 108: 29-35.

[33] Karnib M., Kabbani A., Holail H., Olama Z. 2014. Heavy metals removal using activated carbon, silica and silica activated carbon composite. Energy Procedia 50: 113-120. 